\title{
RELACIONAMENTOS ABUSIVOS: UMA DISCUSSÃO DOS ENTRAVES AO PONTO FINAL
}

\section{Raquel Silva Barretto ${ }^{1}$}

Resumo: Os debates sobre relacionamentos abusivos são atuais e emergentes na nossa sociedade. Por comportarem a violência em suas diversas tipificações e naturezas podem causar impactos na saúde física e psicológica de quem os vivencia. $O$ presente artigo é resultado do trabalho em um Blog. Ao longo do texto foram apresentadas narrativas, com o objetivo de contextualizarem os entraves que dificultam o rompimento dessas relações. A conclusão indica a necessidade de uma análise sobre diversos elementos, como os fatores emocionais, financeiros, sociais, culturais e jurídicos.

Palavras-chave: relacionamentos abusivos, gênero; entraves; violência.

\begin{abstract}
Debates about abusive relationships are current and emerging in our society. Because they involve violence in their various types and natures, they can have an impact on the physical and psychological health of those who experience them. This article is the result of working on a Blog. Throughout the text, narratives were presented, with the purpose of contextualizing the obstacles that impede the disruption of these relations. The conclusion indicates the need for an analysis of various elements, such as emotional, financial, social, cultural and legal factors.
\end{abstract}

Keywords: abusive relationships, genre, barriers, violence.

\section{Introdução}

Atualmente temos nos dados conta do quanto é importante o debate mais aprofundado sobre violências em suas diversas tipificações e naturezas. Embora seja um fenômeno antigo na história humana, estudos sobre as violências tiveram seu auge na década de 1990. 
Para MINAYO (2009, p.21-42) as violências de forma geral representam: "(...) um risco maior para a realização do processo vital humano (...)". A autora menciona que a terminologia no senso comum ainda está muito relacionada à agressão ou coerção física; a violência de natureza psicológica é menos documentada nas pesquisas que envolvem a área da saúde, o que é curioso, já que dela resultam impactos na saúde mental. Alguns grupos são mais vulneráveis ao fenômeno, dentre eles os idosos, crianças, pessoas com deficiência e mulheres. As investigações sobre a violência em consonância com cada grupo trazem importantes desdobramentos, inclusive para pensarmos os relacionamentos abusivos.

Quando falamos das relações abusivas não podemos negar que elas comportam violências principalmente de natureza física, sexual e psicológica. O abuso mantém a relação de poder do abusador sobre o abusado, que é tido como o seu objeto. Para Arendt (1985) a violência surge como última alternativa possivel para manter o poder sobre o outro. Nas relações abusivas, o poder está no cerne da questão, ela demonstra a desigualdade existente entre as forças do abusador e do sujeito que sofre o abuso. O poder é então uma via pela qual a força física ou simbólica será aplicada, no intuito de atingir determinado objetivo.

Segundo Foucault (1995), o poder está presente em todas as relações humanas e pode ser acompanhado da violência para forçar a submissão e a passividade do abusado. As relações de poder são dinâmicas e instáveis, o que significa que não se pode manter o mesmo nível de poder durante todo o tempo. Logo, há uma tomada de consciência por parte daqueles que estão sendo submissos e/ou passivos.

As afirmações dos autores sobre a violência e sua relação com o poder são notáveis, quando analisamos os relacionamentos abusivos. Barretto (2015) definiu esses relacionamentos como aqueles em que há excesso de poder e de controle, culminando no sentimento de posse, na objetificação do outro. Na perspectiva da autora, os relacionamentos abusivos iniciam de modo sutil e podem ultrapassar os limites do que se constitui como "sadio".

Nos consultórios psicológicos, em grupos de ajuda ou blogs envolvendo a temática, as pessoas que chegam na posição de abusadas relatam que na maioria das vezes "se deram conta do poder que o outro estava exercendo sobre elas" ou da "manipulação que ocorria por parte do abusador" em um momento 
onde a violência também se tornou mais nítida.

Ao trabalharmos com relacionamentos abusivos somos questionados sobre $\circ$ que motiva algumas pessoas a não saírem de vez dessa situação. Um dos pontos se dá justamente na dificuldade dos sujeitos perceberem que estão em uma relação abusiva. Em sites que tratam do assunto e oferecem apoio é unânime a presença de tópicos sobre sinais que podem servir de alerta no reconhecimento de um relacionamento abusivo. Como sinais iniciais estão alguns comportamentos e ações muito sutis, que aparecem aos poucos e demandam certo tempo para se agravarem.

O presente artigo é fruto de um estudo de caso. $O$ campo para tal se deu na perspectiva virtual, através de um Blog. Este foi um dos primeiros Blogs brasileiros a propor uma discussão sobre a especificidade da temática. As criadoras do Blog são da área de comunicação social e jornalismo. $O$ intuito principal até então era a divulgação de notícias e materiais, com base nas referências internacionais. Além disso, a página disponibilizava (e mantém até hoje) uma lista atualizada de locais / instituições para que internautas (em situação de violência) possam buscar ajuda nos seus respectivos estados. Os internautas também tinham a possibilidade de fazer contato com a administração da página. E, de fato, muitos contatos e pedidos de ajuda surgiram. Partindo dessa alta demanda, as administradoras criaram uma rede, com profissionais voluntários na área jurídica e na área psicológica. A triagem dos e-mails era feita pelas administradoras e, as mesmas, enviavam os casos para as voluntárias em questão. Seguindo o que é estabelecido pelo Conselho Federal de Psicologia (CRF), não pretendíamos como psicólogas, realizar psicoterapias com os internautas. $O$ trabalho consistia em ler os relatos, oferecer um primeiro apoio e, em seguida, encaminhá-los para instituições ou profissionais que trabalhavam com as questões colocadas. O período em questão ocorreu entre os anos de 2015 e 2017.

As discussões enfatizando os relacionamentos abusivos no cenário brasileiro são muito recentes. Em uma das primeiras teses nacionais sobre o assunto, a psicóloga Tânia Marques Mendonça propôs a análise de Boletins de Ocorrência e entrevistou mulheres que sofreram violência conjugal, entre os anos de 2003 e 2004, em Uberlândia - MG. Ela objetivou analisar os motivos pelos quais as mulheres permanecerem nos relacionamentos, mesmo sendo abusadas. A tese 
foi publicada em 2005. De lá até os anos de 2014/2015 pouco se falou a respeito, embora as produções tenham sido contínuas. No ano de 2015 as administradoras do Blog foram procuradas por uma jornalista, que possuía o interesse de conhecer o trabalho e entrevistar uma das psicólogas. Prontifiquei-me e, nessa entrevista, situei a realidade dos relacionamentos abusivos, conforme os relatos que recebíamos. Na entrevista também sugeri uma reformulação do conceito de "relacionamento abusivo", de acordo com a percepção cotidiana. Até então o conceito preconizado no Brasil englobava um modelo mais norte americano, com foco em padrões comportamentais. $\bigcirc$ que propus foi uma visão mais centrada na objetificação do outro e nos jogos de força, conforme apresentados na introdução. Jogos e disputas de força do "dominador sobre o dominado", o controle sobre o "corpo e a mente de outrem", a posse sobre espaços, limites e fronteiras íntimas. Vi em alguns autores franceses explicações mais abrangentes sobre essa lógica de dominação, que está além da concretude. É uma dominação que também se dá no abstrato, na exigência da atenção, do sentimento, na dominação das emoções e vontades do outro. Para minha surpresa, o conceito reformulado foi citado e continua sendo utilizado em diversas outras produções nacionais. Desde 2015 - tema teve maior repercussão, com base nos acontecimentos elencados pela mídia: as reportagens abordaram mais os abusos, as novelas os colocaram nas tramas e o mesmo se deu em uma situação inesperada dentro de um reality show.

As administradoras, além do Blog, mantinham uma fanpage nas redes sociais, com o mesmo título. Ao longo desse período o número de seguidores teve um crescimento exorbitante. Hoje, em 2018, a página possui 235 mil seguidores.

Atualmente, mais materiais estão acessiveis à população, contudo, ainda existem muitas lacunas no âmbito de produções científicas.

Logo, o objetivo desse trabalho é propiciar um conhecimento científico do tema, com base na aproximação dos elementos reais. A ideia é que essa produção sirva de base para que outros profissionais e/ ou interessados aprofundem as investigações. Por questões éticas, apenas os trechos entre aspas são reais. Os sujeitos dessa publicação receberam nomes aleatórios, as narrativas não apresentam apenas uma história: foram combinadas com elementos fictícios, suprimindo qualquer possibilidade de identificação dos seus atores. 
As narrativas a seguir merecem atenção para a posição dos diferentes envolvidos, frente ao abuso. A observação do abuso nos permite um olhar mais amplo acerca da expressão das violências.

Em um dos primeiros casos atendidos, Joana solicitou ajuda uma vez que estava em um relacionamento há alguns anos e passou por diversas situações até constatar que sofria abusos não só físicos, mas, psicológicos.

Ela descreveu que o seu companheiro "aparentava ser um homem muito carinhoso e preocupado: ele estava quase todos os dias na porta do trabalho dela, ia buscá-la e gostava de levá-la para casa com segurança". Ele sempre deixava claro "o quanto a amava", mas também a incomodava com críticas e demonstrava ciúmes de alguns amigos e amigas, que já faziam parte da vida dela antes mesmo de se conhecerem. As brigas eram frequentes e os motivos pequenos.

Joana por querer agradá-lo, aos poucos foi se distanciando dessas amizades.

Ela constantemente ficava triste por ele implicar com as suas roupas, com o seu corpo e desvalorizá-la nas discussões. Ela contou que se sentia "sem graça".

Com o tempo, o fato dele sempre buscá-la no trabalho passou a incomodarjá que ela desejava "ter alguns momentos sozinha". Joana notou que o temperamento do seu namorado alterava frequentemente e quando foi expor as suas necessidades, se deparou com uma reação explosiva. Desde então a situação piorou muito. $\bigcirc$ ciúme era exagerado, em uma briga ela foi empurrada e se machucou. Todavia, ela acreditava que o mesmo poderia mudar, que tudo aquilo "era por amor", "que ele estava apenas passando por uma fase ruim". E as coisas não mudaram. Vieram ameaças e mais agressões, eles terminaram e voltaram diversas vezes. A história sempre se repetia e Joana se via dentro de uma situação "adoecedora". A ansiedade, o medo e as angústias passaram a ganhar espaços físicos em seu corpo. Ela relatava que sua "gastrite" aparecia diante dos momentos de tensão que vivia. O tempo cronológico foi longo até perceber que era necessário recorrer aos diversos tipos de ajuda disponíveis, embora inicialmente ainda se visse perdida a respeito de quem ou a quais instâncias deveria recorrer e, por isso, escreveu detalhando a sua história e solicitando auxilio. 
No caso apresentado Joana é um nome fictício, mas essa história é uma rotina entre as pessoas que relatam um relacionamento abusivo. $\bigcirc$ período em que os primeiros sinais apareceram até o momento em que Joana se deu conta foi relativamente longo, o que se colocou como uma das dificuldades para encerrar esse relacionamento.

Se as mulheres estão entre os grupos mais susceptiveis à violência, as mesmas também ganham relevância quando o assunto é "relacionamento abusivo". Dentre os pedidos de ajuda ou e-mails que foram enviados diariamente para - Blog até o ano de 2016, cerca de $98 \%$ eram de mulheres.

Não estou afirmando que somente as mulheres sofrem o abuso, estou por ora trazendo um dado real que se cruza com os estudos sobre a violência no país e demonstra maiores taxas em relação às mulheres. Para Araújo (2004) as relações de gênero seriam mais abrangentes quando falamos sobre questões de poder. A violência contra a mulher é uma de suas principais formas, todavia, ela (violência de gênero) também diz respeito aos outros públicos, como é o caso de adolescentes, nas relações de namoro, o que permite pensar os relacionamentos abusivos dentro dessa categoria de violência. Portanto, quando falo sobre a violência contra a mulher e os relacionamentos abusivos ao longo do texto, chamo a atenção para que o leitor não a restrinja ou feche seu campo apenas na visão das mulheres ou da violência doméstica porque apesar dessas circunstâncias serem as de maior visibilidade, elas ocorrem para além disso.

Em 2015, o Mapa da Violência teve como perspectiva a análise dos feminicídios. Entre os anos de 2003 a 2013 o número de vítimas do sexo feminino foi crescente, passando de 3.937 para 4.762, o que significa 13 assassinatos diários de mulheres. Em um grupo homogêneo de 83 países, a Organização Mundial de Saúde (OMS) situou o Brasil como o $5^{\circ}$ no ranking de homicídios femininos. Os principais agressores das jovens e adultas são os parceiros ou ex-parceiros.

Tendo como parâmetro alguns atendimentos na perspectiva dos relacionamentos abusivos, o número de mulheres em relacionamentos homoafetivos que descreveram a parceira como abusadora foi bem menor se comparado ao número de mulheres que sofriam com comportamentos violentos dos seus namorados ou maridos. 
Nesse sentido as dificuldades para sair desses relacionamentos se assemelham com as descritas nas perspectivas da violência contra a mulher. Araújo (2008) situou a construção de uma sociedade patriarcal, que inseriu a mentalidade da dominação dos homens sobre as mulheres, por vezes esse controle se dava através da violência. Não havia permissão, era algo naturalizado e, os relacionamentos em sua maioria heterossexuais, podem ainda comportar tais resquícios. Saffioti (2001, p.121) afirma que:

\footnotetext{
Neste sentido, os homens estão, permanentemente, autorizados a realizar seu projeto de dominação-exploração das mulheres, mesmo que, para isto, precisem utilizar-se de sua força física. Pode-se considerar este fato como uma contradição entre a permissão para a prática privada da justiça e a consideração de qualquer tipo de violência como crime.
}

O abuso engloba uma palavra-chave denominada "consentimento". Cada sujeito sabe até que ponto uma relação é saudável para si ou quais gestos e atitudes é capaz de aceitar dentro desse relacionamento. Uma das questões debatidas atualmente é sobre o abuso sexual dentro de um relacionamento. Se um dos parceiros não consente, o ato ao ocorrer de forma forçada ou obrigatória configura-se como um abuso. Nesse contexto outra situação é um entrave para sair da relação abusiva: a naturalização de alguns comportamentos abusivos e violentos. Observemos o segundo relato.

Leila estava namorando há pouco tempo. Descrevia o seu namorado como "encantador e ciumento". Entretanto, algo lhe causava muito incômodo e vergonha. Ela relatou que estava com ele em uma festa e excedeu os limites da bebida. Chegando no apartamento dele, ele "deu uma forçada para que tivessem a relação sexual". No outro dia acordou e se sentiu muito mal diante de tudo aquilo. Por mais que ela esteja apaixonada, questionou o fato dele ter forçado a barra, mesmo sem ela querer. Mas, alegava o medo de perdê-lo, caso contrariasse a sua vontade.

De um modo simplificado, uma mulher ao ter a relação sexual com o seu parceiro diante de uma imposição dele (contrária à sua vontade), pode não ver tal situação como um abuso/ violência, uma vez que fomos criadas em uma sociedade patriarcal, com o discurso de que "as mulheres devem agradar os seus parceiros" ou ainda "se essa mulher não compreender as necessidades 
sexuais ele terá o direito de procurar outra". Algumas outras atitudes abusivas são tão naturalizadas socialmente nos relacionamentos que passam quase despercebidas: "o ciúme pode ser confundido com amor", "o parceiro pode interferir nas roupas que a parceira usa", "o parceiro pode proibir que a parceira trabalhe porque ele é homem e provedor", entre outras.

Essa naturalização de alguns comportamentos permite até mesmo o abuso físico em um primeiro momento pareça normal. É o caso de um empurrão, de um tapa ou de um puxão dentro de uma briga. Esse tipo de violência é banalizada através de frases como "apenas um tapinha não dói" ou "tapa de amor não faz mal". Segundo Araújo (2008, p.4): "A ideologia de gênero é um dos principais fatores que levam as mulheres a permanecerem em uma relação abusiva. Muitas delas internalizam a dominação masculina como algo natural e não conseguem romper com a situação de violência e opressão em que vivem".

Somado a isso, quando o sujeito que sofre com o abuso é do sexo feminino e decide buscar meios legais para pôr fim a esse relacionamento, os entraves encontrados são os de ordem legal.

Muito se avançou em termos de políticas para coibir a violência contra a mulher; a Lei Maria da Penha, de 2006 faz parte desses avanços. Entretanto, existem lacunas que aparecem na prática. Vasconcellos (2016), ao pesquisar - desdobramento das denúncias feitas por mulheres no Espírito Santo (ES), concluiu que nem todos os profissionais atuantes em órgãos de assistência e defesa às mulheres estão preparados para tal, há uma escassez em termos de recursos financeiros e humanos, as redes são desarticuladas e nem sempre é garantida a segurança efetiva das mulheres em casos de denúncias. A pesquisadora observou ainda que nem todas as mulheres vão à denúncia, seja pelo fato de não quererem se lembrar da situação, pelo medo do que pode ocorrer ou por se sentirem violadas na escuta. Constatou-se, infelizmente, que tais situações se repetem em todo o Brasil. E nos casos em que existem dependentes envolvidos esse processo pode ser ainda mais lento já que outras instâncias são acionadas.

Para além das questões jurídicas, outra dificuldade está no rompimento do vínculo emocional por parte de quem sofre o abuso. É comum os abusadores prometerem mudanças tanto no comportamento que apresentam (agressivo, 
possessivo, extremamente ciumento, violento, explosivo), quanto no relacionamento como um todo. $\mathrm{O}$ abusado pode estar ciente do relacionamento abusivo, mas, geralmente há a crença de que o parceiro irá mudar. $O$ abusador por sua vez costuma a alternar o seu comportamento: em dado momento é descrito como romântico, sensivel, preocupado e, em outro se torna irreconhecivel. Contudo, o seu discurso envolve um jogo emocional. $\bigcirc$ abuso comporta um ciclo. Esse ciclo tem como semelhança algumas fases que envolvem o comportamento do abusador. Em um primeiro momento os casais vivem a fase da "lua de mel", marcados por muita proximidade, romantismo, muitas promessas para o futuro.

Nos relatos, ouvimos comumente que o relacionamento parece não comportar nenhum defeito porque é como se aquele momento de conquista "fugisse à realidade". Não há um tempo determinado para a duração dessa fase. Todavia, com a convivência, os ciúmes ficam aparentes (ciúmes que não tem um foco ou um objeto definido), o sentimento de posse também vai ganhando lugar, e um sujeito passa a impor limites sobre o outro. Essa fase pode culminar com a de "explosão", na qual as brigas e a violência atingem seu ápice: violência psicológica, que pode vir acompanhada em algum momento da física ou sexual. Nesse momento é comum, segundo os casos que nos são repassados, o abusador ou a abusadora ficam "irreconheciveis". Os adjetivos descritos no primeiro momento diluem-se nesta fase e outros como "monstro", "agressivo", "violento", "doente", tomam lugar nos discursos de quem passa por esse momento. Mas, como é um ciclo, tais comportamentos não cessam nessa fase. Essa é uma das fases mais relevantes porque marca o momento em que a maioria dos sujeitos pede ajuda. Entretanto, em um ciclo as fases se repetem diversas vezes até a tomada de consciência. Essa pode ser a fase final para algumas ou a fase que reiniciará o ciclo, para outras. É aqui que a pessoa abusiva geralmente discursa o arrependimento, coloca a possibilidade de mudanças ou transfere a culpa de modo que o outro a assuma, conforme narrado a seguir.

Diferente dos demais casos, Ana se via como abusiva na sua relação. Ela já tinha passado por um histórico de abuso nas relações anteriores mas, agora, buscava ajuda por se perceber cometendo o abuso. Ela relatou que "em determinados momentos era agressiva e não sabia o motivo", "não sabia de onde vinha tal agressividade". Era comum atribuir o motivo das brigas à outra pessoa 
que estava na relação e, por fim, começou a perceber "que essa era uma tentativa de fazer com que o outro se sentisse mal" e, "enquanto o outro pensava que tinha culpa, ele permanecia por perto". Em seguida, ela pedia desculpas porque "algo Ihe fazia lembrar do quanto foi ruim ter sido abusada e, não queria que ninguém sentisse aquilo". Mas, o seu comportamento alimentava esse ciclo, para ela e para quem estava com ela. A dificuldade nessa narrativa está nos dois lados: abusado e abusador não conseguem se desvencilhar da relação.

Ainda como dificuldade, podemos situar o isolamento social em que o abusado se encontra. É comum ouvirmos que o abusador "tinha ciúmes ou não gostava de determinadas pessoas", assim, o abusado foi ao longo do tempo diminuindo a sua rede social e consequentemente perdendo contatos importantes. Dentro do jogo emocional, o abusador também é capaz de inferiorizar o abusado. Nessa situação o sujeito ao tentar sair da relação geralmente sustenta a baixa estima e sente-se sozinho, sem uma rede de apoio sólida. Há uma falta de confiança em si e no outro ou um sentimento de que outras pessoas podem depositar "descrédito" no seu pedido de ajuda.

O quarto entrave aqui trazido seria em termos financeiros, quando há uma relação de dependência por parte do abusado. Este depende da renda do abusador por estar desempregado ou por possuírem algum bem em comum, que serve de subsistência. Principalmente nos casos das mulheres, há uma lógica consciente ou inconsciente capaz de justificar a sua permanência em um relacionamento abusivo. Nesse sentido, a permuta, o medo, a falta de recursos para a sobrevivência, dentre outros fatores emocionais, são justificativas para a "submissão" feminina. (MARQUES, 2005 apud MILLER, 1999).

São vários os entraves encontrados. Há um círculo vicioso do abuso que comporta diferentes naturezas da violência e necessita ser quebrado. Um relacionamento tem o encantamento inicial, fase de idealização. No relacionamento abusivo, a tensão precede o encantamento e situações irrelevantes causam "tempestades em copo d’água", o abusado sente-se confuso ou culpado. Em seguida ocorrem as brigas, abusos verbais, emocionais e físicos. Comumente o sujeito abusador convence o seu alvo de que este último o fez perder a cabeça e busca apaziguar o ocorrido. A fase de lua de mel 
é então vivenciada e as juras de amor e promessas são constantes. As fases se reiniciam e se repetem inúmeras vezes até o sujeito abusado se dar conta de que apesar dos entraves necessita buscar apoio e quebrar esse ciclo.

Ao longo do artigo compartilhei um pouco da experiência e dos discursos aparentes no atendimento às pessoas que sofrem com o abuso. Vale ressaltar que os abusados podem ser homens ou mulheres. Não se pode fechar os olhos para o abuso que ocorre em relações homoafetivas e essa questão é de grande importância já que poucos são os dados sobre a violência entre casais do mesmo sexo no Brasil.

Tampouco, conforme diz Saffioti (2001), nada impede que determinada mulher pratique violência contra o seu parceiro. Entretanto, quando analisamos as mulheres dentro de uma categoria social, o histórico de dominação-exploração não obedece a mesma lógica histórica da imposição do poder por parte dos homens. Ressaltei a importância das relações de gênero pela dominação culminar em violências não só no âmbito do domicilio ou não se restringir somente aos adultos, visto que adolescentes também vivenciam relações abusivas entre si. A opção por uma ênfase nas mulheres se deu apenas por uma maior demanda desse público.

Conforme debatemos, a violência traz sérios impactos para a saúde / vida das pessoas que estão nesse ciclo e torna-se necessário sair dele. A tendência social é culpabilizar e questionar quem sofre o abuso, por não romper tal ciclo de violência, contudo, a percepção do relacionamento como abusivo é difícil e, quando isso ocorre outros fatores estão agregados. Existem facilitadores primordiais nesse rompimento e o principal é o estabelecimento de uma rede de apoio. Uma ou mais pessoas que o abusado possa contar serão essenciais no primeiro momento já que o medo do agressor, a vergonha por ser vítima e o isolamento se fazem presentes.

Além dessas pessoas centrais, o abusado também pode buscar apoio em grupos online ou em serviços especializados (assistenciais e jurídicos). Nesse processo, a busca pela psicoterapia é fundamental, uma vez que trabalhará o sofrimento e outras perspectivas futuras do sujeito.

\section{Referências}

ARAÚJO, M. F; MARTINS, E. J. S.; SANTOS, A L. Violência de Gênero 
e Violência Contra a Mulher. In: ARAÚJO, M. F.; MATTIOLI, O. (orgs.) Gênero e Violência. São Paulo: Arte \& \& Ciência, 2004.

ARAUJO, M. F. Gênero e violência contra a mulher: o perigoso jogo de poder e dominação. Psicol. Am. Lat., México, n. 14, 2008. Disponivel em <http://pepsic.bvsalud.org/scielo.php?script=sci_arttext\&pid=\$1870$350 \times 2008000300012 \&$ lng=pt\&nrm=iso $>$. Acessado em 03/05/2018.

ARENDT, H. Da Violência. Editora: Universidade de Brasilia, 1985.

BARRETTO, R.S. Psicóloga explica relacionamento abusivos: o que é e como sair dessa situação. 2015. Entrevista. UNESP, São Paulo, 2015. Disponivel em:< http://reporterunesp.jor.br/2015/08/20/psicologa-explicarelacionamentos-abusivos-o-que-e-e-como-lidar-com-essa-situacao/>. Acessado em: 20/12/2017.

FOUCAULT, M. O sujeito e o poder. In: DREYFUS, H.; RABINOW, P.Michel Foucault: Uma trajetória filosófica. Para além do estruturalismo e da hermenêutica. Rio de Janeiro: Forense Universitária, 1995. p. 231-249.

MARQUES, T. M. . Violência conjugal: estudo sobre a permanência da mulher em relacionamentos abusivos. Dissertação de Mestrado, Universidade Federal de Uberlândia, Uberlândia, 2005.

MILLER, M. S. Feridas invisíveis. São Paulo: Summus, 1999.

MINAYO, M. C. S. Conceitos, teorias e tipologias de violências: a violência faz mal à saúde individual e coletiva. In: NJAINE, K; ASSIS, S. G.;

CONSTANTINO, P. (Org.). Impactos da Violência na Saúde. Rio de Janeiro; Ed. Fiocruz, 2009.

SAFFIOTI, H. I. B. Contribuições feministas para o estudo da violência de gênero. Cadernos Pagu, v. 16, 2001.

VASCONCELLOS, N. M. A. A violência contra a mulher: uma análise dos desdobramentos da denúncia na cidade de Vitória/ES. 2016. $89 \mathrm{f}$. Tese (Mestrado em Saúde Pública) - Escola Nacional de Saúde Pública Sergio Arouca, Fiocruz, Rio de Janeiro. 2016.

WAISELFISZ, J. J. Mapa da violência 2015: Homicídio de mulheres no Brasil [Internet]. Brasilia: Secretaria Nacional de Juventude; 2015. Disponível em: http://www.mapadaviolencia.org.br/pdf2015/MapaViolencia_2015_ mulheres.pdf. Acessado em: 16/03/2017. 
Recebido em dezembro de 2017

Aceito para publicação em maio de 2018 